\title{
Problems of Professional Self-Development Among Undergraduates in the Digital Space, Identified During the COVID-19 Pandemic
}

\author{
Tatyana Bashkireva ${ }^{1, *}$, Anastasia Bashkireva ${ }^{1}$, Alexander Morozov ${ }^{2}$, Alexey Kuraev $^{3}$, and \\ Elena Nebrodovskaya-Mazur ${ }^{4}$ \\ ${ }^{1}$ Ryazan State University named after S.A. Yesenin, 390000 Ryazan, Russia \\ ${ }^{2}$ Research Institute of the of the Federal penitentiary service of Russia, 125130 Moscow, Russia \\ ${ }^{3}$ Moscow state University of technology and management named after K.G. Razumovsky, 109004 \\ Moscow, Russia \\ ${ }^{4}$ Institute of world civilizations, 107078 Moscow, Russia
}

\begin{abstract}
The article examines the problems of professional selfdevelopment among undergraduates in the digital space, identified during the COVID-19 pandemic. The results of the study showed that students have characteristics that are necessary for further personal growth. They want to know themselves and ready to change and learn new things, improve themselves. Conducted during a pandemic and distance learning in selfisolation showed that $50 \%$ of students expressed satisfaction with this form of education, explaining their opinion with a high level of independent search for the necessary information, opportunities for self-development, self-realization, and self-improvement. Among the difficulties of distance learning, all surveyed identified: search and critical analysis of digital information; communicative dissatisfaction, the need for approval. The surveyed students in their self-development need a micro- and macroenvironment that would create a secure creative educational space. It is necessary to search for new solutions to overcome psychological barriers associated with the need for self-development as future highly qualified specialists in the context of modern trends in the development of digital education.
\end{abstract}

\section{Introduction}

Due to the intensive development of scientific and technological progress, digitalization in all spheres of social activity, the renewal of professions takes about 5-10 years. Professional organizations always adapt to the changing conditions of social development and balance between traditional and innovative approaches to learning. The teaching community believes that training, education is a system in which traditional, and modern trends in development education close to intertwined and interrelated [3].

The inclusion of innovative communication technologies in professional education presupposes independent professional information by the subject/person. The Internet is full

\footnotetext{
* Corresponding author: bashkirevat@bk.ru
} 
of a wide variety of information, often far from critical, scientific, students have trouble in choosing problem high-quality subject knowledge. Comprehension of the material search is broke limited to viewing several sources. Unfortunately, library attendance is declining. Since the Internet space very actively saturated with various information, users have the opportunity to search and choose what matters to them. However, this is not always correct, useful and scientific information. Participants in this space use webinars and courses for their training. The intensive use of digital technologies at all stages of education development, online learning technologies, educational activity in the virtual space (for example, in social networks) - leads to the fact that a person in the educational space leaves a digital footprint. [2].

Tracking the cognitive interests of students, professional expectations possible based on digital data already now, through fixing a digital footprint. As the more detailed the digital trace, the more accurate the recommendations for the critical acquisition of information in the digital space and communication knowledge and assistance in modelling selfdevelopment and professional growth in the future [7].

The concept of self-development presupposes the independent acquisition of professional knowledge by a subject or person motivated by it. Digital transformation is changing the content, forms and methods of education. Digitization primarily affects the education system at school and university. In this respect, an interesting example is Stanford University, which in 2016 began a transition to a new concept - Open Loop University Stanford 2025. An interesting project of a similar University of the National Technological Initiative (NTI) "20.35" in Russia opened within the framework of this program.

In professional self-development, there are three main directions: a) acquisition of new knowledge; b) reflection; c) the acquisition and use of self-regulation skills.

Reflection includes in the competencies of modern curricula in all areas of study. Researchers identify several main methods of reflexive analysis: individual (autoreflection) and group with the participation of a consultant psychologist. Emotions and feelings that a person experiences when analyzing actions and behaviour individually or in a group are most important. They characterize the positive or negative emotions of a person, which are necessary for critical analysis [1].

For example, a person with a high level of professional reflection will not be jealous of their colleagues, positively assesses individual personality traits and will encourage them in professional activities, since he understands the extent of their benefits for teamwork. With a low level - will envy and hinder the implementation of the creative individuality of his colleagues in professional activities. The acquisition and use of self-regulation skills play a significant role in the professional development of an individual [4-5].

The COVID-19 pandemic has made its adjustments in vocational education [6]. It became clear that digitalization entered education and caused problems that we had not previously noticed [8-9]. We must accept this situation. Learn to live and work in a new space. One of these problems is the study of the readiness of future highly qualified specialists for selfrealization, the degree of self-realization skills. It led to the goal of our exploration. To study the problems of self-development of students in the process of developing professional activities identified during the COVID-19 pandemic.

\section{Materials and Method}

In the research, we used the methodology of V. Pavlov, valid and popular in Russia, Readiness for self-development. The essence of the method for studying the readiness of an individual to know himself, the world around him, to improve himself. It includes four blocks: 1) I can improve myself, but I don't want to know about myself; 2) I want to know 
myself, I can change myself; 3) I don't want to know myself, I don't want to change; 4) I want to know about myself, but I cannot change myself.

The data obtained processed mathematically and statistically $(\mathrm{M} \pm \mathrm{m} ; \pm \delta ; \rho)$. Students were examined $(n=24)$. These are boys and girls students at different faculties.

\section{Results and discussion}

The COVID-19 pandemic has made its adjustments to the global educational space and is called the "Era of the COVID-19 pandemic." Education turned out to be unprepared for distance and digital education both on the part of teachers and students. The participants in the educational space divided into two conflicting sides: those who quickly adapted to it and those who are not ready, and, therefore, do not want to accept it. However, the inevitability lies in the fact that it is no longer possible to return to traditional education in the form in which it was. It is a new step in education.

The readiness of future specialists for self-development, self-regulation is of no small importance in professional activity. Our research has shown that one of the significant problems faced by students and undergraduates during the period of distance learning was the need for self-realization, the search for their style of professional activity, selfactualization in professional development. Nevertheless, how to realize yourself, to achieve success?

Our research conducted during the period of a pandemic and distance learning in selfisolation showed that $50 \%$ of students expressed satisfaction with this form of education, explaining their opinion with a high level of independent search for the necessary information, opportunities for self-development, self-realization, and self-improvement. There are time and additional opportunities for self-development. Among the difficulties of distance learning, all surveyed identified: search and critical analysis of information; communicative dissatisfaction, the need for approval.

An analysis of the results of readiness for self-development showed that $95.8 \%$ of the surveyed ( $90 \%$ of boys and $88 \%$ of girls) have characteristics for further personal growth. They want to know themselves, to change and learn new things, improve themselves.

The study of statistical indicators did not reveal any significant difference between I want to know and I want to improve in boys $(\mathrm{t}=1 ; 43 ; \mathrm{P}>0.001)$ and girls $(\mathrm{t}=0.24 ; \mathrm{P}>0.001)$. There were also no significant differences between boys and girls in terms of "want to know" $(\mathrm{t}=1 ; 64 ; \mathrm{P}>0.001)$ and "want to improve" $(\mathrm{t}=0.3 ; \mathrm{P}>0.001)$.

Correlation analysis showed that young men had a significant connection between I want to know, I want to improve $(\rho=0.86 ; \mathrm{P}<0.001)$. The higher the level of desire among young people to know about themselves, the higher the level of wish for self-improvement. In girls, on the contrary, the higher desire to learn about themselves, the lower the desire to improve themselves $(\rho=-0.48 ; \mathrm{P}<0.05)$.

Both boys and girls had problems that hinder self-development. For girls, such difficulties as were typical:

- fear of failure;

- doubts about personal characteristics that correspond to the chosen profession;

- an unwillingness to know shortcomings;

- waiting for the support of approval from others;

- the importance of circumstances in achieving success.

In $4.2 \%$ of the surveyed, the desire for self-development is above than the desire to understand and change oneself. It is due to a lack of confidence in the chosen profession. Boys and girls $(50 \%)$ associate their failures with insufficient experience in applying theoretical knowledge in practice. Among young men, 10\% are not interested in the opinion of others about their qualities and capabilities. 
In connection with the information received, a model of psychological and pedagogical support of students to the professional activity developed. The purpose of the developed model was to assist students in identifying professionally significant personality traits and in shaping the desire for self-development and self-improvement.

We have formulated tasks for the implementation of the maintenance model:

- development of ideas about significant personality traits that are in demand in future professional activities using digital technologies;

- formation of the ability to analyze and determine psychological characteristics and people around (to reflect) in a remote format of professional activity;

- creating a sense of group cohesion and creating an atmosphere of mutual trust in the remote format of professional activity;

- the use of exercises that contribute to the actualization of personal resources, striving for self-development and self-improvement, taking into account professional activities in the digital space.

In the process of implementing the model, the individual reasons for previous experience identified, which were barriers to readiness for self-development and self-realization. For example, it turned out that the school and university did not pay enough attention to the moral and ethical characteristics of a specialist in the chosen professional activity. It paid little attention to vocational guidance. Teachers with an authoritarian teaching style harmed the self-development of the subjects. In the process of training, the creative potential of the individual in educational organizations was not in demand.

\section{Conclusion}

As our studies have shown, this problem is necessary not so much theoretically as practically. In the process of self-development, undergraduates need a micro-and macro-environment that would create a secure creative educational space. Allow them to be open, inspiring confidence. The opportunity to discuss, share their ideas, achievements, plans.

The results obtained allow us to state that the examined undergraduates have individual barriers to self-realization, the origins of which lie in childhood and at various stages of age development. Distance learning, to which educational organizations have switched due to the intensive spread of coronavirus infection and the need for self-isolation, including in Russia, have actualized the problem of self-development in professional activities. It is necessary to search for new solutions to overcome psychological barriers associated with the need for selfrealization of future highly qualified specialists in the trends of the modern development of the digital educational space.

\section{References}

1. Björn B.de Koning, Gertjan Rop, Fred Paas, Computers in Human Behavior, 110, 106379 (2020)

2. Claudine Zorn, Marie-Laurence Feffer, Jean-Philippe Dillenseger, Journal of Medical Imaging and Radiation Sciences (2020)

3. Danielle V. Eusuf, Emma L. England, Mike Charlesworth, Clifford L. Shelton, Sarah J. Thornton, British Journal of Anaesthesia, 125(5), 432 (2020)

4. Kinga Lachowicz Tabaczek, Beata Bajcar, Personality and Individual Differences, 131, 197 (2018)

5. Kyungmee Lee, Hyoseon Choi, Young Hoan Cho, The Internet and Higher Education, 41, 25 (2019) 
6. Lokanath Mishra, Tushar Gupta, Abha Shree, Int. J. of Educational Research Open (2020)

7. Matthijs Vink, Thomas Edward Gladwin, Sanne Geeraerts, Pascal Pas, Dienke Bos, Marissa Hofstee, Sarah Durston, Wilma Vollebergh, Developmental Cognitive Neuroscience, 45, 100829 (2020)

8. Roberto D. Costa, Gustavo F. Souza, Ricardo A.M. Valentim, Thales B. Castro, Cognitive Systems Research, 64, 134 (2020)

9. Y. Punie, European J. of Education, 42, 185 (2008) 